\title{
MicroRNA-28-5p inhibits the migration and invasion of gastric cancer cells by suppressing AKT phosphorylation
}

\author{
FANGTAO XIAO $^{1 *}$, ZHENGUO CHENG ${ }^{2 *}$, PENGLIANG WANG $^{1}$, BAOHENG GONG $^{1}$, \\ HANWEI HUANG ${ }^{1}$, YANAN XING ${ }^{1}$ and FUNAN LIU ${ }^{1}$ \\ ${ }^{1}$ Department of Surgical Oncology and General Surgery, The First Affiliated Hospital of China Medical University; \\ ${ }^{2}$ Department of Cell Biology, Key Laboratory of Cell Biology, Ministry of Public Health, and Key Laboratory of \\ Medical Cell Biology, Ministry of Education, China Medical University, Shenyang, Liaoning 110001, P.R. China
}

Received August 7, 2016; Accepted September 13, 2017

DOI: $10.3892 / \mathrm{ol} .2018 .8603$

\begin{abstract}
Gastric cancer is a polygenic disease with a high mortality rate worldwide. Although a number of dysregulated genes have been confirmed to be involved in development and progression of gastric cancer, the molecular mechanisms by which this occurs remain unclear. The present study identified that microRNA (miR-28-5p) was involved in the migration and invasion of gastric cancer cells, and was able to affect the prognosis of patients with gastric cancer. Reverse transcription-quantitative polymerase chain reaction analysis indicated that the expression of miR-28-5p was significantly downregulated in gastric cancer tissues, and that patients with higher expression had a good prognosis. miR-28-5p expression was significantly associated with depth of invasion, lymph node metastasis and pathological stage. Gastric cancer cells overexpressing miR-28-5p exhibited a marked reduction of migration and invasion by Transwell and wound scratch assay. The phosphorylation of RAC serine/threonine-protein kinase (AKT), which affected cellular invasion and metastasis, was significantly inhibited by overexpression of miR-28-5p. In conclusion, miR-28-5p is a tumor suppressor that inhibits gastric cancer cell migration and invasion through repressing AKT phosphorylation. miR-28-5p may therefore represent a
\end{abstract}

Correspondence to: Dr Funan Liu, Department of Surgical Oncology and General Surgery, The First Affiliated Hospital of China Medical University, 155 Nanjing North Street, Heping, Shenyang, Liaoning 110001, P.R. China

E-mail:1fn540@126.com

*Contributed equally

Abbreviations: RT-qPCR, reverse transcription-quantitative polymerase chain reaction; miRNA/miR, microRNA; Pak1, p21-activated kinase-1; Pak4, p21-activated kinase-4; ERK, extracellular-signal regulated kinase; JAK, Janus kinase; JNK, c-Jun $\mathrm{N}$-terminal kinase

Key words: microRNA-28-5p, gastric cancer, migration, invasion, $\mathrm{RAC}$ serine/threonine-protein kinase potential biomarker for the prognosis of gastric cancer and a novel therapeutic target in advanced gastric cancer.

\section{Introduction}

Gastric cancer is one of the malignant tumor with the highest mortality rates worldwide (1). Although the incidence and mortality rates of gastric cancer have declined globally, it remains the second most common cause of cancer-associated mortality (2). A total of $>70 \%$ of cases occur in developing countries and half of cases occur in Eastern Asia, primarily in China $(3,4)$. Invasion and metastasis are the primary reasons that lead to gastric cancer-associated mortalities. Investigating molecular mechanisms of invasion and metastasis is of great value for the diagnosis, treatment and prevention of gastric cancer. In the past several decades, a number of molecular mechanisms have been investigated, but the role of microRNAs (miRNAs/miRs) in gastric cancer remains to be elucidated.

miRNAs are non-coding RNA molecules containing $\sim 20$ nucleotides in length that are major post-transcriptional regulators. miRNAs regulate numerous cellular processes, including cellular proliferation, apoptosis, differentiation, invasion and metastasis (5). miRNAs may undergo aberrant regulation during carcinogenesis and serve as oncogenes or tumor suppressors (6). Aberrant expression of miRNAs is common in various human malignancies and may modulate cancer-associated genomic regions or fragile sites (7). miR-28 is an important miRNA, including miR-28-5p and miR-28-3p. A large body of evidence indicates that the abnormality of miR-28 expression is associated with carcinogenesis of breast cancer (8), colorectal cancer (9), B-cell lymphoma (10), glioma and renal cell carcinoma (11). However, studies concerning the role of miR-28-5p in human gastric cancer remain to be performed.

The present study profiled the expression of miR-28-5p in 91 gastric cancer tissue and adjacent normal mucosal tissue pairs by reverse transcription-quantitative polymerase chain reaction (RT-qPCR). In addition, gastric cancer BGC823 and SGC7901 cells were infected with miR-28-5p mimics to evaluate the role of mir-28-5p in gastric cancer. Low-expression of miR-28-5p in gastric cancer tissues with poor prognosis was identified, and miR-28-5p was demonstrated to serve a role in 
inhibiting gastric cancer migration and invasion. These results indicate that miR-28-5p may be a potential biomarker and therapeutic target against gastric cancer.

\section{Materials and methods}

Clinical samples. Fresh samples of 91 pairs of gastric cancer and adjacent normal mucosal tissues farthest from the tumor $(>5 \mathrm{~cm})$ were obtained from patients who underwent surgical resection for gastric cancer diagnosed based on the 7 th edition of American Joint Committee on Cancer Tumor Node Metastasis (TNM) staging system (12) in the First Affiliated Hospital of China Medical University (Shenyang, China) between March 2007 and November 2008. The aforementioned samples were frozen in liquid nitrogen and kept at $-80^{\circ} \mathrm{C}$ instantly until they were experimentally utilized. The present study was approved by the Medical Ethics and Human Clinical Trial Committee at the First Hospital of China Medical University and each patient provided written informed consent for their inclusion in the present study.

Cell culture. Human gastric cancer BGC823 and SGC7901 cell lines obtained from the Department of Cell Biology, China Medical University were incubated in a humidified incubator at $37^{\circ} \mathrm{C}$ with $5 \% \mathrm{CO}_{2}$, and cultured in Dulbecco's modified Eagle's medium (DMEM; Gibco; Thermo Fisher Scientific, Inc., Waltham, MA, USA). DMEM was supplemented with 10\% fetal bovine serum (Gibco; Thermo Fisher Scientific, Inc.), $100 \mathrm{U} / \mathrm{ml}$ penicillin and $100 \mathrm{U} / \mathrm{ml}$ streptomycin according to the supplier's protocol.

Construction of stable cell lines. To construct a stable miR-28-5p-overexpressing cell line, BGC823 and SGC7901 cells in the logarithmic growth phase in 6-well plates were infected with $50 \mu \mathrm{l}\left(1 \times 10^{8} \mathrm{TU} / \mathrm{ml}\right)$ commercial lentiviral packaged pre-miR-28 and the control lentivirus (Shanghai GeneChem Co., Ltd., Shanghai, China). The negative control short hairpin RNA sequence was 5'-TTCTCCGAACGT GUCACGT-3'. After 24 h, DMEM containing puromycin (Sigma-Aldrich; Merck KGaA, Darmstadt, Germany) was used to culture and select stable cell lines for two weeks prior to subsequent phenotypic and functional analyses.

$R N A$ extraction and $R T-q P C R$. Total RNA was extracted from frozen tissue samples with TRIzol ${ }^{\circledR}$ reagent (Invitrogen; Thermo Fisher Scientific, Inc.). Next, miRNA was purified with the mirVana miRNA Isolation kit (Ambion; Thermo Fisher Scientific, Inc.) according to the manufacturer's manual. cDNA was synthesized using the PrimeScript ${ }^{\mathrm{TM}}$ RT Reagent kit (Takara Biotechnology Co., Ltd., Dalian, China). qPCR was performed as previously described (13) to detect the expression level of miR-28-5p in the 91 pairs of human gastric and adjacent normal mucosal tissue samples. The expression of miRNAs was calculated relative to U6 small nuclear RNA. All the quantitation of PCR data was presented as fold-change and calculated using the $2^{-\Delta \Delta \mathrm{Cq}}$ method (14). Primers used were as follows: miR-28-5p reverse transcription primer, 5'-CTC AACTGGTGTCGTGGAGTCGGCAATTCAGTTGAGCTC AATAG-3'; miR-28-5p forward primer, 5'-GCGGAAGGA GCTCACAGTCT-3'; miR-28-5p reverse primer, 5'-TGGTGT
CGTGGAGTCG-3'; U6 forward primer, 5'-CTCGCTTCG GCAGCACA-3'; U6 reverse primer, 5'-AACGCTTCACGA ATTTGCGT-3'.

MTT assay. The proliferative rates were assessed by MTT assay. The stable infected cells and control cells were inoculated in 96-well plates at a density of $2 \times 10^{3}$ cells/well and cultured for 1-6 days. At 24, 48, 72, 96, 120 and 144 h, $20 \mu 1$ MTT $(10 \mathrm{mg} / \mathrm{ml})$ was added to cells and they were incubated for $4 \mathrm{~h}$ at $37^{\circ} \mathrm{C}$. Next, dimethyl sulfoxide was added to solubilize the formazan product for $20 \mathrm{~min}$ at room temperature. The absorbance was determined at $490 \mathrm{~nm}$ with a spectrophotometer. All experiments were performed three times in triplicate.

Cell cycle analysis. BGC823 and SGC7901 cells $\left(5 \times 10^{5}\right)$ were cultured for $48 \mathrm{~h}$ in 6-well plates, and then digested, washed with cold PBS and fixed in $100 \%$ precooled methanol overnight at $4^{\circ} \mathrm{C}$. Cells were washed with cold PBS again, re-suspended in PBS solution containing $100 \mu \mathrm{g} / \mathrm{ml}$ propidium iodide and $20 \mu \mathrm{g} / \mathrm{ml}$ RNase A (Omega Bio-Tek, Inc., Norcross, GA, USA), and incubated at $37^{\circ} \mathrm{C}$ for $30 \mathrm{~min}$. Next, the cells were measured using a flow cytometer and analyzed with FACSCalibur $^{\mathrm{TM}}$ (BD Biosciences, Franklin Lakes, NJ, USA) and FlowJo software (version 7.6.1; Tree Star, Inc., Ashland, OR, USA).

Adhesion assay. BGC823 and SGC7901 cells were seeded on 24-well plates at equal numbers $\left(\sim 2 \times 10^{4}\right)$, incubated for $20 \mathrm{~min}$ and washed three times with PBS to remove the non-adherent cells. Next, cells were fixed by $4 \%$ paraformaldehyde for $30 \mathrm{~min}$, and stained with $0.4 \%$ Trypan Blue for $20 \mathrm{~min}$ at room temperature. Cells were then counted under a light microscope in 20 independent symmetrical visual fields at a magnification of $x 400$.

Wound scratch assay. Equal numbers $\left(\sim 2 \times 10^{5}\right)$ of stably infected cells and control cells were incubated in 6-well plates equal numbers for $24 \mathrm{~h}$ until they reached $90-100 \%$ confluence. The capacity of movement on cells was detected by wound-healing assay. Briefly, a scratch was made across the center of the cell monolayer in each well using sterile $200-\mu 1$ pipette tip and the medium was replaced with fresh medium. The scratch distance between the two linear regions was imaged and measured at different time points using an inverted microscope.

Transwell assay. For the cell migration assay, $\sim 1 \times 10^{5}$ cells were harvested, re-suspended in serum-free DMEM, and added to the top chamber of 24-well Transwell chambers (Corning Incorporated, Corning, NY, USA) with a pore size of $8.0 \mu \mathrm{m}$; the lower chamber was filled with $500 \mu \mathrm{l}$ DMEM with $10 \%$ fetal bovine serum. Cells were fixed with $100 \%$ precooled methanol for 10 min and stained with $0.4 \%$ Trypan Blue following incubation at $37^{\circ} \mathrm{C}$ for $24 \mathrm{~h}$. Cells on the top chambers were removed by a cotton swab. The number of cells that invaded to the bottom surface was counted using a light microscope. The invasion assay was performed as migration assay, with the exception that the cells were seeded onto the filters of the Transwell chambers with coated Matrigel. 
A

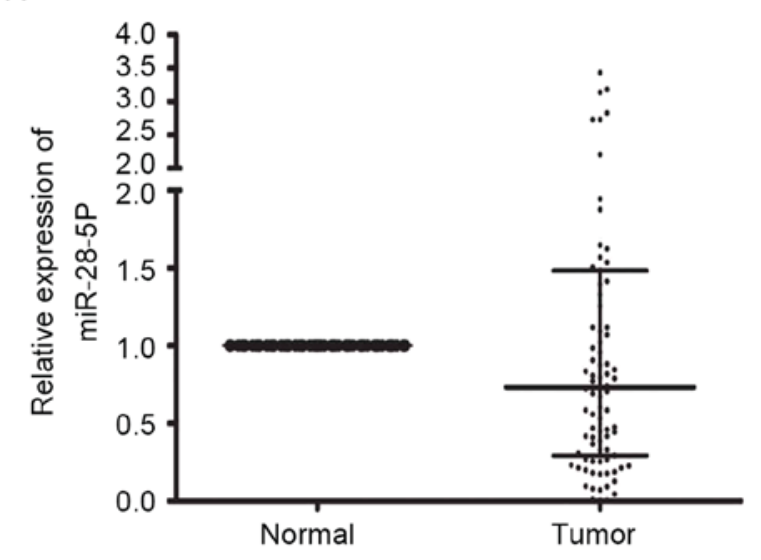

B

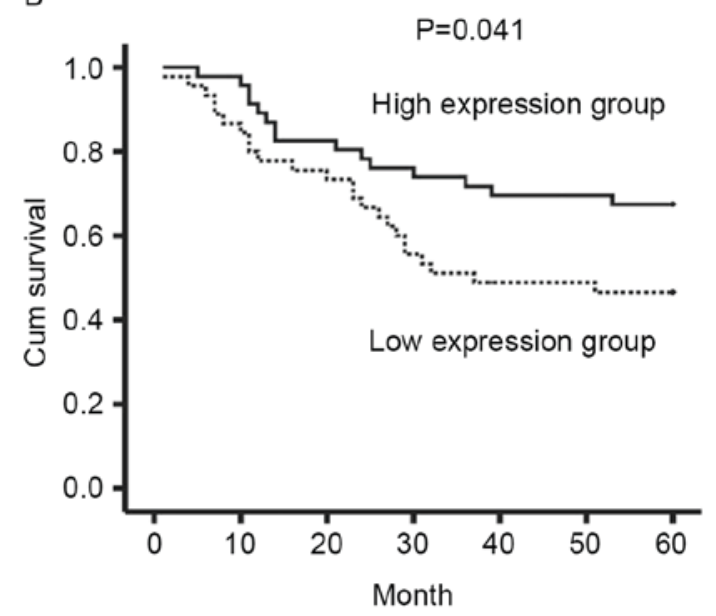

C

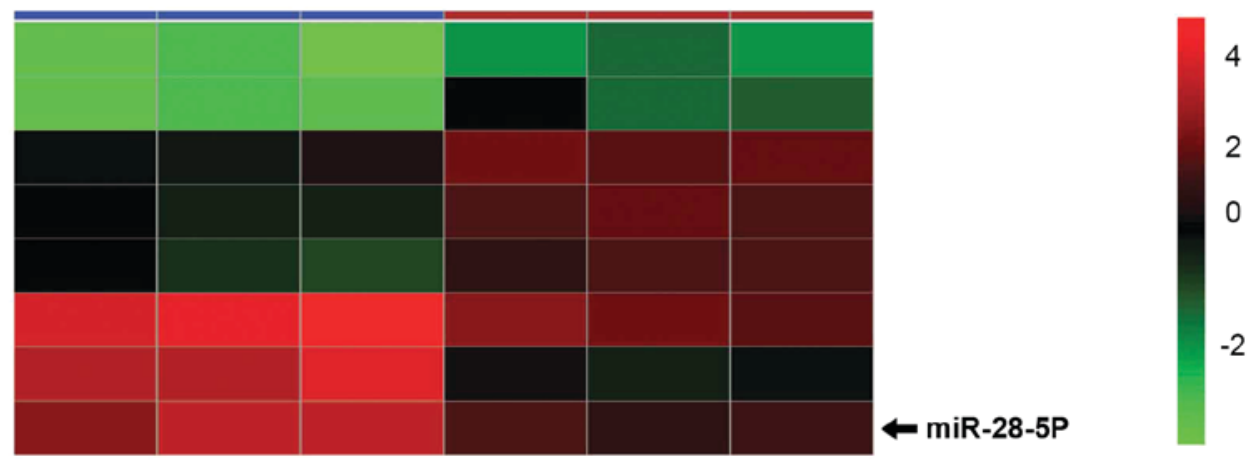

Figure 1. miR-28-5p is downregulated in gastrointestinal cancer, which is associated with poorer patient prognosis. miR-28-5p expression reduced in gastric cancer tissues. (A) miR-28-5p expression in 91 pair gastric cancer tissues and corresponding non-tumor adjacent tissues was assessed using reverse transcription-quantitative polymerase chain reaction analysis (normal vs. tumor, $\mathrm{P}<0.01$ ). (B) Downregulation of miR-28-5p expression is associated with poor patient prognosis. Kaplan-Meier survival analysis of 91 gastric cancer patients was performed on miR-28-5p high- and low-expression groups of gastric cancer tissues. (C) miR-28-5p expression was also reduced in colorectal cancer tissues ( $\mathrm{P}<0.001)$. Heat map displaying the expression levels of miR-28-5p in 3 paired colorectal cancer tissues and adjacent non-tumor tissues. The data was obtained from published expression dataset GSE39845 of the National Center for Biotechnology Information Gene Expression Omnibus database. miR-28-5p, microRNA-28-5p.

Protein extraction and western blot analysis. Total protein was extracted from cells using ice-cold radioimmunoprecipitation assay buffer supplemented with phenylmethylsulfonyl fluoride and protease inhibitor cocktail (Sigma-Aldrich; Merck KGaA). ABCA kit with Varioskan multimode microplates spectrophotometer from Thermo Fisher Scientific Inc. (Waltham, MA, USA) was used to detect the concentration of protein in the supernatant. A total of $20 \mu \mathrm{g}$ protein/well was fractionated by $10 \%$ SDS-PAGE and transferred to a polyvinylidene fluoride membrane. Membranes were blocked at room temperature for $2 \mathrm{~h}$ with $5 \%$ non-fat dry milk in Tris-buffered saline containing 0.1\% Tween-20 (TBST) and incubated with P-ERK (1:1,000; Cell Signaling Technology; cat. no. 9101), P-Pak1 (1:1,000; Thermo Fisher Scientific; cat. no. PA5-37677), P-Pak4 (1:1,000; Cell Signaling Technology; cat. no. 3241) and P-AKT (1:1,000; Cell Signaling Technology; cat. no. 4060) at $4^{\circ} \mathrm{C}$ overnight. The membranes were washed in TBST and incubated with a horseradish peroxidase (HRP)-conjugated secondary antibody (Goat anti-rabbit, 1:5,000; ZSGQ-BIO; cat. no. ZF-0311) for $2 \mathrm{~h}$ at room temperature. Bound antibody complexes were detected and visualized by ECL western bolting detection kit (Ambion; Thermo Fisher Scientific, Inc.).

Independent verified data set from the NCBI-Gene Expression Omnibus (GEO) database. The GSE39845 dataset was downloaded from the GEO database (http://www.ncbi.nlm.nih.gov/geo/, accessed on December 10th 2015). The GSE39845 contained six colorectal cancer samples (three normal vs. three cancer samples). The platform was based on the GPL14613 (miRNA-2) Affymetrix Multispecies miRNA-2 Array. Then, the preprocessing of Microarray Data was conducted by Affy package in $\mathrm{R}$ software (R software, version 3.2.1; Affy package, version 1.56.0; http://www.r-project.org/, accessed on December 5th 2015), and differentially expressed miRNA was identified by the limma package in R software (limma package, version 3.34.6). Only the differentially expressed miRNA with $\mathrm{P}<0.05$ and $\mid \log 2$ (fold-change) $\mid>1.5$ were screened out, as calculated by Student's t-test. To additionally visualize differentially expressed miRNA, the heatmap was constructed using the Pheatmap package in R (Pheatmap package, version 1.0.8; http://www.r-project.org/). 
Table I. Association between the expression of miR-28-5p with clinicopathological features in patients with gastric cancer.

\begin{tabular}{|c|c|c|c|}
\hline Parameter & $\mathrm{n}$ & $\operatorname{miR}-28-5 p$ fold ${ }^{a}$ & P-value ${ }^{b}$ \\
\hline \multicolumn{4}{|l|}{ Age, years } \\
\hline$<65$ & 59 & $0.77(0.29-1.57)$ & \multirow[t]{2}{*}{0.536} \\
\hline$\geq 65$ & 32 & $0.65(0.30-1.11)$ & \\
\hline \multicolumn{4}{|l|}{ Gender } \\
\hline Male & 69 & $0.82(0.34-1.52)$ & \multirow[t]{2}{*}{0.082} \\
\hline Female & 22 & $0.40(0.28-0.79)$ & \\
\hline \multicolumn{4}{|l|}{ Location } \\
\hline Upper third & 4 & $0.23(0.11-0.38)$ & \multirow[t]{4}{*}{0.131} \\
\hline Middle third & 12 & $0.62(0.26-1.01)$ & \\
\hline Lower third & 63 & $0.74(0.31-1.54)$ & \\
\hline Extensive & 12 & $1.00(0.42-2.47)$ & \\
\hline \multicolumn{4}{|l|}{ Gross type } \\
\hline Localized & 11 & $0.37(0.10-1.54)$ & \multirow[t]{2}{*}{0.247} \\
\hline Infiltrative & 80 & $0.76(0.31-1.47)$ & \\
\hline \multicolumn{4}{|c|}{ Size (max. diameter), $\mathrm{cm}$} \\
\hline$<5$ & 42 & $0.76(0.41-1.65)$ & \multirow[t]{2}{*}{0.324} \\
\hline$\geq 5$ & 49 & $0.67(0.23-1.40)$ & \\
\hline \multicolumn{4}{|c|}{ Histological type } \\
\hline Intestinal & 48 & $0.64(0.26-1.08)$ & \multirow[t]{2}{*}{0.120} \\
\hline Diffuse & 43 & $0.84(0.39-1.95)$ & \\
\hline \multicolumn{4}{|c|}{ Depth of invasion (pT) } \\
\hline $\mathrm{T}_{1}, \mathrm{~T}_{2}, \mathrm{~T}_{3}$ & 59 & $0.81(0.39-1.95)$ & \multirow[t]{2}{*}{0.024} \\
\hline $\mathrm{T}_{4}$ & 32 & $0.50(0.22-0.94)$ & \\
\hline \multicolumn{4}{|c|}{ Lymph node status (pN) } \\
\hline $\mathrm{N}_{0}, \mathrm{~N}_{1}, \mathrm{~N}_{2}$ & 62 & $0.79(0.37-1.71)$ & \multirow[t]{2}{*}{0.035} \\
\hline $\mathrm{N}_{3}$ & 29 & $0.56(0.19-0.99)$ & \\
\hline \multicolumn{4}{|c|}{ Lymph node metastasis } \\
\hline No & 24 & $0.95(0.43-2.06)$ & \multirow[t]{2}{*}{0.222} \\
\hline Yes & 67 & $0.71(0.27-1.12)$ & \\
\hline \multicolumn{4}{|c|}{ Lymphatic invasion } \\
\hline No & 72 & $0.76(0.31-1.47)$ & \multirow[t]{2}{*}{0.667} \\
\hline Yes & 19 & $0.71(0.20-1.88)$ & \\
\hline \multicolumn{4}{|c|}{ AJCCTNM stage } \\
\hline I, II, IIIa, IIIb & 79 & $0.79(0.33-1.57)$ & \multirow[t]{2}{*}{0.030} \\
\hline IIIc, IV & 12 & $0.44(0.18-0.80)$ & \\
\hline
\end{tabular}

${ }^{\mathrm{a}}$ Median of relative expression, with 25-75th percentile in parenthesis. ${ }^{\mathrm{b}}$ Mann-Whitney test (for two groups) or Kruskal Wallis test (for $>2$ groups). miR-28-5p, microRNA-28-5p; AJCC, American Joint Committee on Cancer; TNM, tumor node metastasis.

Statistical analysis. Continuous variables for the summary statistics of the study are presented as mean \pm standard deviation, or as median value with interquartile ranges. The experimental data were analyzed by SPSS 16.0 software (SPSS, Inc., Chicago, IL, USA). Differences were considered statistically significant when $\mathrm{P}<0.05$. Mann-Whitney test (for two groups) or Kruskal-Wallis test (for $>2$ groups) were used to analyze the association between the expression of miR-28-5p and clinicopathological features in patients with gastric cancer. Survival curves were produced using the Kaplan-Meier method. The log-rank test was used to analyze survival difference. Student's t-test was used to analyze other parameters of phenotypes of gastric cancer cells.

\section{Results}

Clinical significance of miR-28-5p in gastric cancer tissues. Previous reports have identified that the expression of miR-28-5p was abnormal in various tumors $(9,15-19)$. The present study used RT-qPCR to detect the expression level of miR-28-5p in 91 gastric cancer tissues and corresponding non-tumor adjacent tissues. As presented in Fig. 1A, the 
A

BGC823

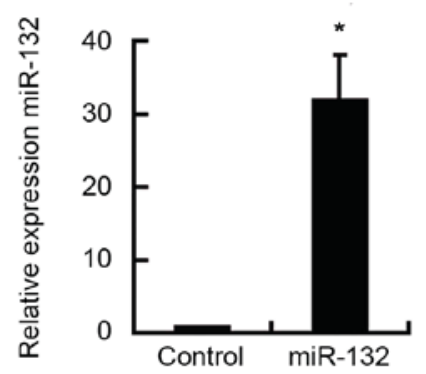

B

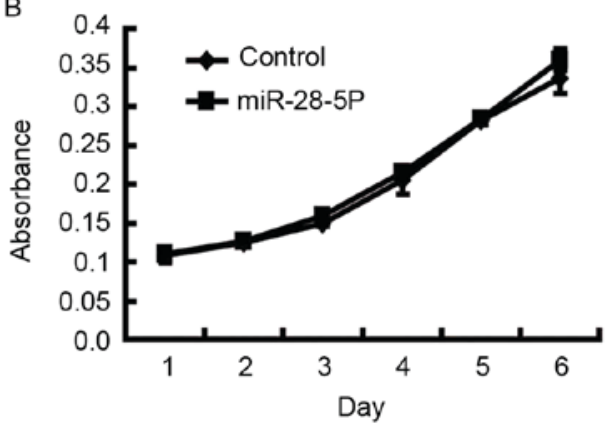

C

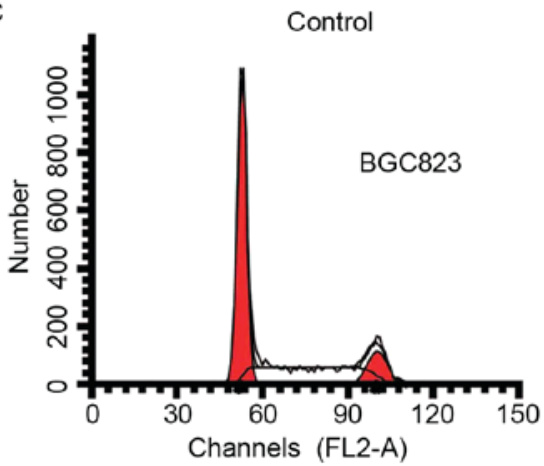

D

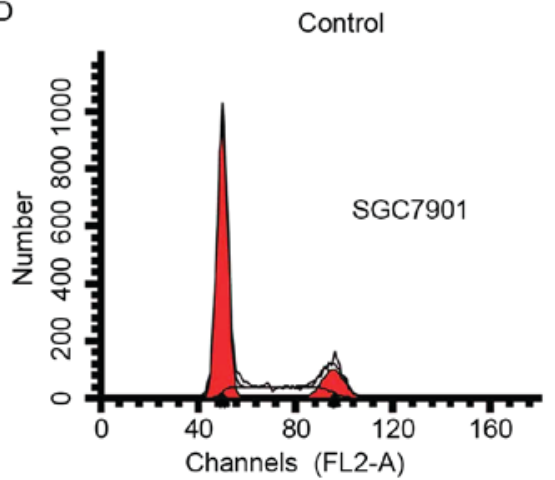

SGC7901
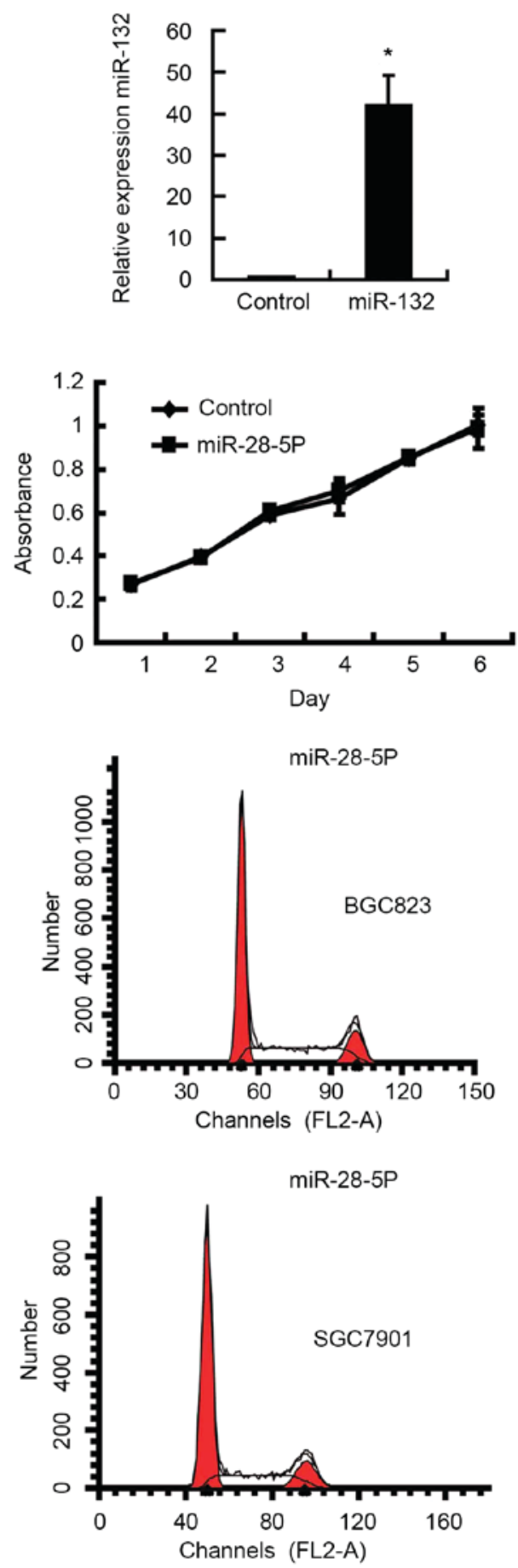

Figure 2. miR-28-5p has no effect on cell proliferation and cell cycle. (A) Reverse transcription-quantitative polymerase chain reaction analysis of the relative levels of miR-28-5p in BGC823 and SGC7901 cells infected with miR-28-5p lentivirus and selected by puromycin. "P<0.01 vs. control. (B) miR-28-5p did not affect gastric cell proliferation. MTT assay was detected in BGC823 and SGC7901 cells overexpressing miR-28-5p and control cells on days 1-6. (C and D) miR-28-5p did not affect the cell cycle of gastric cancer cells. The cell cycle was analyzed in BGC823 and SGC7901 cells overexpressing miR-28-5p and control cells. miR-28-5p, microRNA-28-5p.

expression level of miR-28-5p was reduced significantly in gastric cancer tissues compared with corresponding non-tumor adjacent tissues $(\mathrm{P}<0.01)$. The association between the expression of miR-28-5p and the clinicopathological factors of gastric cancer was further analyzed (Table I). No statistical difference between miR-28-5p expression, and age, gender, location, grosstype, size, histological type and lymphatic invasion was identified. The expression level of mir-28-5p in gastric cancer tissues from patients with TNM stage IIIC and stage IV disease was significantly lower compared with that in gastric cancer tissues from patients with TNM stage I, II, IIIA, and IIIB disease $(\mathrm{P}=0.030)$. The miR-28-5p level was significantly reduced in the $\mathrm{T} 4$ group compared with that in $\mathrm{T} 1, \mathrm{~T} 2$ and $\mathrm{T} 3$ groups $(\mathrm{P}=0.024)$. In addition, a significantly lower 
A
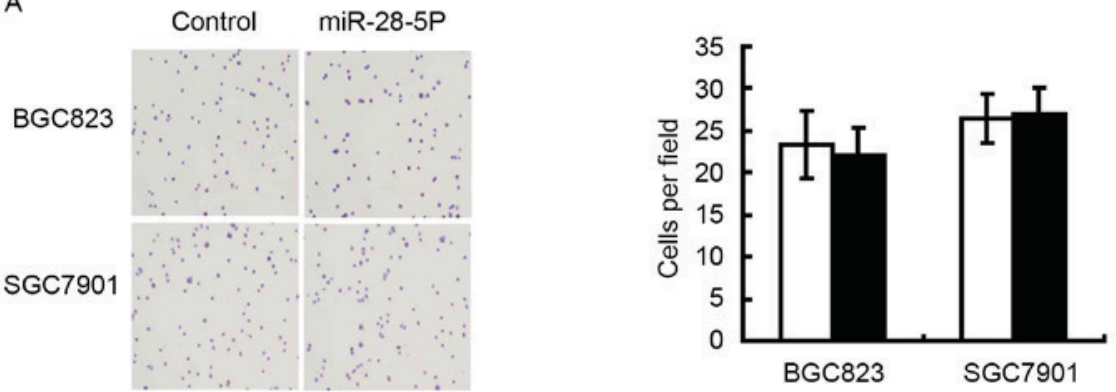

B BGC823
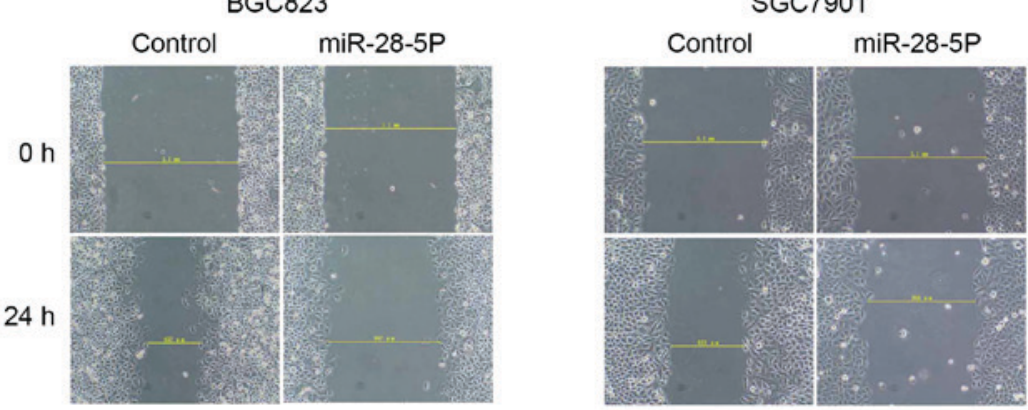

C

BGC823
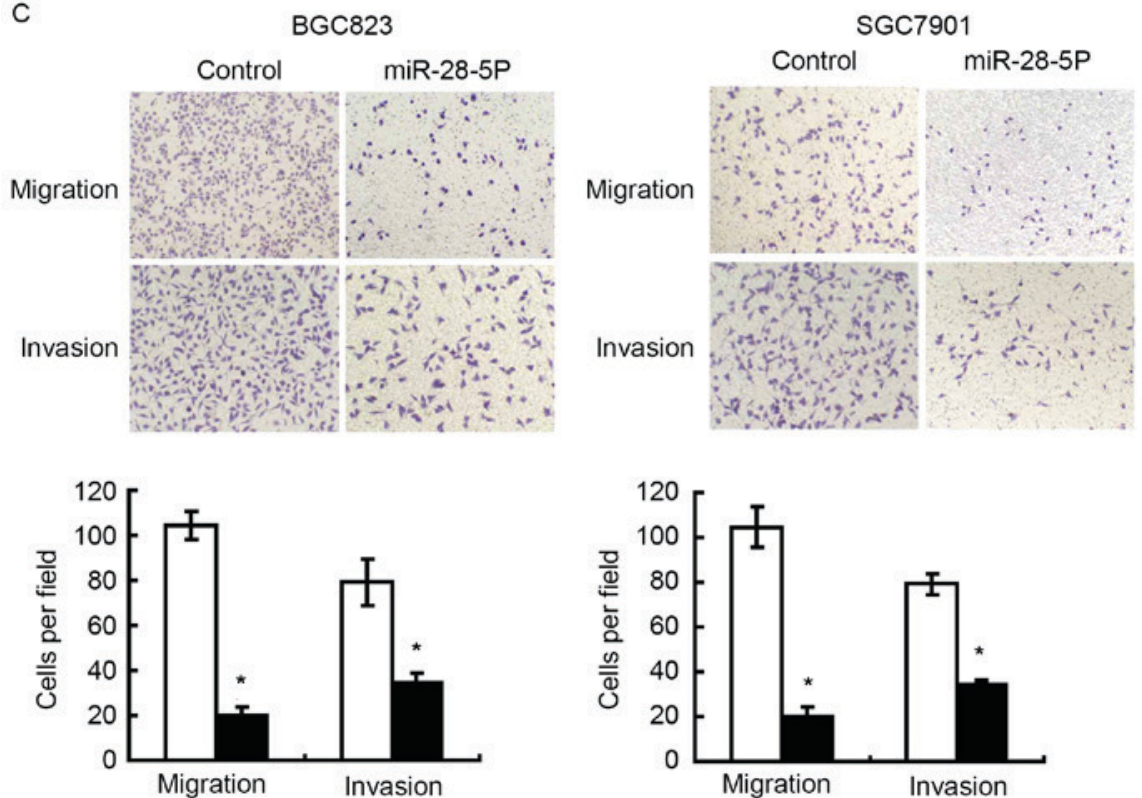

Figure 3. miR-28-5p inhibits migration and invasion potential of gastric cancer cells but not adhesion. (A) miR-28-5p did not affect cell adhesion. Cells overexpressing miR-28-5p and control cells were assessed using a cell adhesion assay. Representative photomicrographs are shown (original magnification, $\mathrm{x} 100$ ). The cell number was counted in 20 independent symmetrical visual fields at a magnification of x400. (B and C) miR-28-5p inhibited gastric cancer cell migration and invasion ability. (B) Wound healing assay in BGC823 and SGC7901 cells overexpressing miR-28-5p and in control cells. (C) Transwell migration and invasion assays were performed in BGC823 and SGC7901 cells with overexpressing miR-28-5p and in control cells. Representative photomicrographs are shown (original magnification, $\mathrm{x} 100$ ). The cell number was counted in 20 independent symmetrical visual fields at an original magnification of $\mathrm{x} 400$. ${ }^{*} \mathrm{P}<0.01$ vs. control. miR-28-5p, microRNA-28-5p.

expression level of miR-28-5p was observed in gastric cancer tissues from patients with $\mathrm{N}_{3}$ lymph node status compared with that in gastric cancer tissues from patients with $\mathrm{N}_{0}, \mathrm{~N}_{1}$ and $\mathrm{N}_{2}$ lymph node status $(\mathrm{P}=0.035)$. Kaplan-Meier survival curve analysis illustrated that the overall survival time was significantly longer in patients with higher miR-28-5p expression, compared with patients with lower miR-28-5p expression $(\mathrm{P}=0.041$; Fig. 1B). The dividing standard was that if the median value was $>0.73$-fold, the patients were in the higher
miR-28-5p expression group, whereas if the median value was $\leq 0.73$-fold, the patients were in the lower miR-28-5p expression group. Based on the Limma package, the published expression dataset GSE39845 of the National Center for Biotechnology Information Gene Expression Omnibus database was analyzed and the differentially expressed miRNAs between colorectal cancer and paired normal tissues were obtained. The results of the analysis indicated that miR-28-5p expression was downregulated in colorectal cancer tissues $(\mathrm{P}<0.001)$, which 


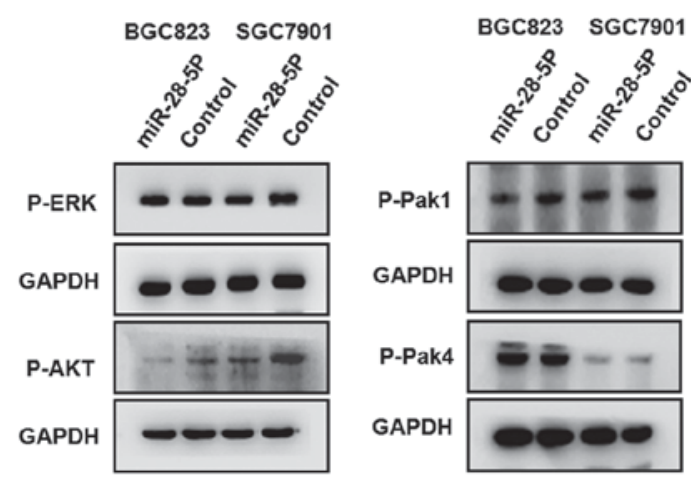

Figure 4. miR-28-5p inhibits the phosphorylation of AKT in gastric cancer cells. The phosphorylation levels of ERK, Pak1, Pak4 and AKT in BGC823 and SGC7901 cells overexpressing miR-28-5p and control cells were detected by western blot analysis. GAPDH served as protein loading control. AKT, RAC serine/threonine-protein kinase; P-ERK, phosphorylated extracellular signal-regulated kinase; Pak1, p21-activated kinase 1; miR-28-5p, microRNA-28-5p.

demonstrated that the expression of miR-28-5p was markedly reduced in colorectal tumors, compared with corresponding normal tissues (Fig. 1C).

miR-28-5p inhibits the migration and invasion of gastric cancer cells. To investigate the functional significance of miR-28-5p overexpression in gastric cancer, miR-28-5p-lentivirus infection was used to establish stable BGC823 and SGC7901 cell lines overexpressing miR-28-5p. Fig. 2A demonstrated that expression of miR-28-5p was significantly increased in BGC823 and SGC7901 cell lines following infection with miR-28-5p-lentivirus. To characterize the functionofmiR-28-5pin gastric cancer progression, the effect of miR-28-5p expression on the proliferation of gastric cancer cells was detected using an MTT assay and flow cytometry analysis. No statistically significant difference was identified in the proliferative ability of cells overexpressing miR-28-5p compared with the control cells (Fig. 2B). Similarly, cell cycle analysis also revealed that there were no significant differences between the cells overexpressing miR-28-5p and control cells (Fig. 2C and D). A cell adhesion assay was performed to assess whether miR-28-5p expression affected cell adhesion capability of gastric cancer cells, and revealed that upregulation of miR-28-5p exhibited no effect on cell adhesion (Fig. 3A). Wound-scratch and cell migration assays were performed to evaluate whether miR-28-5p was able to affect the migration of gastric cancer cells. Fig. $3 \mathrm{~B}$ and $\mathrm{C}$ revealed that there was a significant inhibition in migration in cells infected with miR-28-5p mimics compared with cells infected with negative control. In Fig. 3C, an invasion assay revealed miR-28-5p inhibited the invasion ability of gastric cancer cells.

Overexpressing miR-28-5p inhibits the phosphorylation of $R A C$ serine/threonine-protein kinase (AKT) in gastric cancer cells. Previous studies have validated thatP21-activated kinase-1 (Pak1) (20), P21-activated kinase-4 (Pak4) (21), extracellular-signal regulated kinase (ERK) (22) and AKT (23) are involved in invasion and metastasis of gastric cancer. Western blotting detected the phosphorylation level of Pak1, Pak4, ERK and AKT protein in BGC823, and SGC7901 cells overexpressing miR-28-5p. Only the phosphorylation level of AKT protein revealed a marked reduction in BGC823 and SGC7901 cells overexpressing miR-28-5p, compared with cells that were infected with negative control (Fig. 4). These results revealed that overexpression miR-28-5p inhibited the phosphorylation of AKT protein in gastric cancer cells.

\section{Discussion}

Gastric cancer is the second-leading cause of cancer-associated mortality in the world (24). A large proportion of gastric cancer patients, particularly in China, are diagnosed at advanced stage with metastasis, and therefore are unable to undergo curative resection $(25,26)$. It has been documented that patients with advanced stage gastric cancer have a poor prognosis, with a reduced 5-year survival rate (27). Therefore, metastasis is a key event in determining the prognosis of gastric cancer. miRNAs possess essential roles in angiogenesis and cancer metastasis (28). The Snail-regulated miR-375 inhibited the migration and invasion of gastric cancer cells partially by targeting Janus kinase 2 (JAK2) (29). Liu et al (30) reported that miR-10b promoted the invasion of gastric cells by activating RhoC-AKT signaling, through targeting homeobox protein Hox-D10. Mir-28-5p has been reported to be associated with development and progression of a number of tumors, including hepatocellular carcinoma, colorectal cancer and renal cell carcinoma $(9,17,31,32)$. However, the role of miR-28-5p in gastric cancer remains unknown. The present study revealed the significant downregulation of miR-28-5p in gastric cancer tissues. The overall survival time was significantly longer in patients with higher miR-28-5p expression compared with those with low expression. Detailed analysis of miR-28-5p expression and the clinicopathological characteristics of gastric cancer revealed significant association between the expression level of miR-28-5p, and depth of invasion, lymph node status and TNM stage. The data indicated that the expression of miR-28-5pwas clinically relevant and maybe a potent biomarker for the prognosis of gastric cancer.

The present study investigated the biological function of miR-28-5p in gastric cancer in vitro. MTT assay and flow cytometry analysis revealed that overexpression of miR-28-5p in human gastric cell line BGC823 and SGC7901 did not affect cellular proliferation, and cell cycle progression. To further characterize the role of miR-28-5p in invasion and metastasis of gastric cancer, cell adhesion, wound healing, migration, and invasion assays were performed. Overexpression of miR-28-5p inhibited the migratory and invasive ability of gastric cancer cells, but not the adhesion ability (Fig. 3). These data suggested that miR-28-5p might be a tumor suppressor gene, which inhibited the invasion and metastasis of gastric cancer.

ERK, Pak1, Pak4 and AKT have been reported to be involved in the invasion and metastasis of gastric cancer. ERK signaling pathway can be activated by transforming growth factor- $\beta$ to regulate the invasion and metastasis of gastric cancer (33). Pak1 activates ERK and c-Jun N-terminal kinase (JNK) to induce the metastasis of gastric cancer (34). Pak4 kinase mediates the phosphorylation of stathmin 2 to promote the invasive potential of gastric cancer cells (21). AKT has three isoforms, AKT1, AKT2 and AKT3, and serves an essential role in the regulation of diverse cellular functions, including cell 
growth, proliferation, glucose metabolism, survival, genome stability, transcription and neovascularization (35). AKT signaling regulates the epithelial-mesenchymal transition, affecting the migration and invasion of circulating gastric cancer cells (36). Western blot analysis was used to profile the phosphorylation level of ERK, Pak1, Pak4 and AKT in BGC823, and SGC7901 cells overexpressing miR-28-5p. The results revealed that overexpression of miR-28-5p markedly inhibited the phosphorylation level of AKT, but not ERK, Pak1 and Pak4, in gastric cancer cells. Overexpression of miR-28-5p reduced the migratory and invasive capacity of gastric cancer cells, and the possible mechanism may involve the inhibition of the activation of the AKT signaling pathway via miR-28-5p.

In summary, to the best of our knowledge, the present study demonstrated that miR-28-5p expression was significantly downregulated in gastric cancer and associated with poor gastric cancer patient prognosis for the first time. miR-28-5p, as a tumor suppressor, inhibited gastric cancer cell invasion and metastasis by repressing the phosphorylation level of AKT. miR-28-5p may be a potential biomarker for prognosis of gastric cancer and a therapeutic target for the treatment of advanced gastric cancer.

\section{Acknowledgements}

Not applicable.

\section{Funding}

This study was supported by grants from the National Natural Science Foundation of China (grant no. 81001092) and Natural Science Foundation of Liaoning (grant no. 2013021097). The funding body had no role in the design the study and collection, analysis, and interpretation of data and in writing the manuscript.

\section{Availability of data and materials}

All data generated or analyzed during this study are included in this published article.

\section{Authors' contributions}

FX, ZC and FL conceived and designed the study. FX, ZC and HH performed the experiments. PW and BG performed the statistical and bioinformatics analyses. YX performed statistical analyses. FX and ZC wrote the manuscript. YX and FL revised the final manuscript. All authors read and approved the final manuscript.

\section{Ethics approval and consent to participate}

Our study was approved by the Medical Ethics and Human Clinical Trial Committee at the First Hospital of China Medical University and the written informed consent of each patient included in our study was also provided.

\section{Consent for publication}

All patients have provided the written informed consent for the publication for the associated data.

\section{Competing interests}

The authors declare that they have no competing interests.

\section{References}

1. Arnold M, Moore SP, Hassler S, Ellison-Loschmann L, Forman D and Bray F: The burden of stomach cancer in indigenous populations: A systematic review and global assessment. Gut 63: 64-71, 2014.

2. Ferlay J, Shin HR, Bray F, Forman D, Mathers C and Parkin DM: Estimates of worldwide burden of cancer in 2008: GLOBOCAN 2008. Int J Cancer 127: 2893-2917, 2010.

3. Yang L: Incidence and mortality of gastric cancer in China. World J Gastroenterol 12: 17-20, 2006.

4. Fock KM and Ang TL: Epidemiology of Helicobacter pylori infection and gastric cancer in Asia. J Gastroenterol Hepatol 25: 479-486, 2010.

5. Zhao X, Li X and Yuan H: microRNAs in gastric cancer invasion and metastasis. Front Biosci (Landmark Ed) 18: 803-810, 2013.

6. Ventura A and Jacks T: MicroRNAs and cancer: Short RNAs go a long way. Cell 136: 586-591, 2009.

7. Wagner S, Ngezahayo A, Murua Escobar H and Nolte I: Role of miRNA let-7 and its major targets in prostate cancer. Biomed Res Int 2014: 376326, 2014.

8. Yang M, Yao Y, Eades G, Zhang Y and Zhou Q: miR-28 regulates Nrf2 expression through a Keap1-independent mechanism. Breast Cancer Res Treat 129: 983-991, 2011.

9. Almeida MI, Nicoloso MS, Zeng L, Ivan C, Spizzo R, Gafà R, Xiao L, Zhang X, Vannini I, Fanini F, et al: Strand-specific miR-28-5p and miR-28-3p have distinct effects in colorectal cancer cells. Gastroenterology 142: 886-896 e9, 2012.

10. Schneider C, Setty M, Holmes AB, Maute RL, Leslie CS Mussolin L, Rosolen A, Dalla-Favera R and Basso K: MicroRNA 28 controls cell proliferation and is down-regulated in B-cell lymphomas. Proc Natl Acad Sci USA 111: 8185-8190, 2014.

11. Malzkorn B, Wolter M, Liesenberg F, Grzendowski M, Stühler K, Meyer HE and Reifenberger G: Identification and functional characterization of microRNAs involved in the malignant progression of gliomas. Brain Pathol 20: 539-550, 2010.

12. Edge SB, Byrd DR, Compton CC, Fritz AG, Greene FL and Trotti A (eds): AJCC Cancer Staging Manual. 7th edition. Springer-Verlag, New York, pp347-377, 2010.

13. Cheng Z, Liu F, Wang G, Li Y, Zhang H and Li F: miR-133 is a key negative regulator of CDC42-PAK pathway in gastric cancer. Cell Signal 26: 2667-2673, 2014.

14. Livak KJ and Schmittgen TD: Analysis of relative gene expression data using real-time quantitative PCR and the 2(-Delta Delta C(T)) method. Methods 25: 402-408, 2001.

15. Li Z, Gu X, Fang Y, Xiang J and Chen Z: microRNA expression profiles in human colorectal cancers with brain metastases. Oncol Lett 3: 346-350, 2012.

16. Li LL, Qu LL, Fu HJ, Zheng XF, Tang CH, Li XY, Chen J, Wang WX, Yang SX, Wang L, et al: Circulating microRNAs as novel biomarkers of ALK-positive nonsmall cell lung cancer and predictors of response to crizotinib therapy. Oncotarget 8: 45399-45414, 2017.

17. Zhou SL, Hu ZQ, Zhou ZJ, Dai Z, Wang Z, Cao Y, Fan J, Huang XW and Zhou J: miR-28-5p-IL-34-macrophage feedback loop modulates hepatocellular carcinoma metastasis. Hepatology 63: 1560-1575, 2016.

18. Lim EL, Trinh DL, Scott DW, Chu A, Krzywinski M, Zhao Y, Robertson AG, Mungall AJ, Schein J, Boyle M, et al: Comprehensive miRNA sequence analysis reveals survival differences in diffuse large B-cell lymphoma patients. Genome Biol 16: 18, 2015.

19. Rizzo M, Berti G, Russo F, Evangelista M, Pellegrini M and Rainaldi G: The miRNA pull out assay as a method to validate the miR-28-5p targets identified in other tumor contexts in prostate cancer. Int J Genomics 2017: 5214806, 2017.

20. Wang G, Zhang Q, Song Y, Wang X, Guo Q, Zhang J, Li J, Han Y, Miao Z and Li F: PAK1 regulates RUFY3-mediated gastric cancer cell migration and invasion. Cell Death Dis 6: e1682, 2015.

21. Guo Q, Su N, Zhang J, Li X, Miao Z, Wang G, Cheng M, Xu H, Cao L and Li F: PAK4 kinase-mediated SCG10 phosphorylation involved in gastric cancer metastasis. Oncogene 33: 3277-3287, 2014. 
22. Fukui H, Zhang X, Sun C, Hara K, Kikuchi S, Yamasaki T, Kondo T, Tomita T, Oshima T, Watari J, et al: IL-22 produced by cancer-associated fibroblasts promotes gastric cancer cell invasion via STAT3 and ERK signaling. Br J Cancer 111: 763-771, 2014.

23. Sasaki T and Kuniyasu H: Significance of AKT in gastric cancer (Review). Int J Oncol 45: 2187-2192, 2014.

24. Danaei G, Vander Hoorn S, Lopez AD, Murray CJ and Ezzati M; Comparative Risk Assessment collaborating group (Cancers) Causes of cancer in the world: Comparative risk assessment of nine behavioural and environmental risk factors. Lancet 366 1784-1793, 2005.

25. Shen L, Shan YS, Hu HM, Price TJ, Sirohi B, Yeh KH, Yang YH, Sano T, Yang HK, Zhang X, et al: Management of gastric cancer in Asia: Resource-stratified guidelines. Lancet Oncol 14: e535-e547, 2013

26. Takahashi T, Saikawa Y and Kitagawa Y: Gastric cancer: Current status of diagnosis and treatment. Cancers (Basel) 5: 48-63, 2013.

27. Hochwald SN, Kim S, Klimstra DS, Brennan MF and Karpeh MS: Analysis of 154 actual five-year survivors of gastric cancer. J Gastrointest Surg 4: 520-525, 2000.

28. Zhong J, Chen Y and Wang LJ: Emerging molecular basis of hematogenous metastasis in gastric cancer. World J Gastroenterol 22: 2434-2440, 2016.

29. Xu Y, Jin J, Liu Y, Huang Z, Deng Y, You T, Zhou T, Si J and Zhuo W: Snail-regulated miR-375 inhibits migration and invasion of gastric cancer cells by targeting JAK2. PLoS One 9: e99516, 2014

30. Liu Z, Zhu J, Cao H, Ren H and Fang X: miR-10b promotes cell invasion through RhoC-AKT signaling pathway by targeting HOXD10 in gastric cancer. Int J Oncol 40: 1553-1560, 2012.
31. Shi X and Teng F: Down-regulated miR-28-5p in human hepatocellular carcinoma correlated with tumor proliferation and migration by targeting insulin-like growth factor-1 (IGF-1). Mol Cell Biochem 408: 283-293, 2015.

32. Wang C, Hu J, Lu M, Gu H, Zhou X, Chen X, Zen K, Zhang CY, Zhang T, Ge J, et al: A panel of five serum miRNAs as a potential diagnostic tool for early-stage renal cell carcinoma. Sci Rep 5: $7610,2015$.

33. $\mathrm{Fu} \mathrm{H}, \mathrm{Hu} \mathrm{Z}$, Wen J, Wang $\mathrm{K}$ and Liu Y: TGF-beta promotes invasion and metastasis of gastric cancer cells by increasing fascin 1 expression via ERK and JNK signal pathways. Acta Biochim Biophys Sin (Shanghai) 41: 648-656, 2009.

34. Li LH, Luo Q, Zheng MH, Pan C, Wu GY, Lu YZ, Feng B, Chen XH and Liu BY: P21-activated protein kinase 1 is overexpressed in gastric cancer and induces cancer metastasis. Oncol Rep 27: 1435-1442, 2012.

35. Bellacosa A, Kumar CC, Di Cristofano A and Testa JR: Activation of AKT kinases in cancer: Implications for therapeutic targeting. Adv Cancer Res 94: 29-86, 2005.

36. Yuan D, Xia H, Zhang Y, Chen L, Leng W, Chen T, Chen Q, Tang Q, Mo X, Liu M and Bi F: P-Akt/miR-200 signaling regulates epithelial-mesenchymal transition, migration and invasion in circulating gastric tumor cells. Int J Oncol 45: 2430-2438, 2014. 